This is an open access article under the CC BY-NC-ND license (https://creativecommons.org/licenses/by-nc-nd/3.0/) Issue III, November 2020

ISSN 2707-9481

ISBN 978-601-323-207-2

https://doi.org/10.31643/2020.003

\author{
Arapbek Aitzhanov \\ Abai Kazakh National Pedagogical University, Kazakhstan \\ E-mail: arapbek_86-86@mail.ru \\ ORCID ID: 0000-0003-1164-2431
}

\title{
Role of Education Assessment for Education Management
}

\begin{abstract}
The author studied the role of education assessment for education management. Humanity was particularly revered by oratorical people who were educated at any age. In ancient Greece, during the Olympic Games, in addition to sports competitions, scholars and poets also publicized their works. According to legend, Herodotus' work "History" was introduced to the public during the Olympics and spread throughout the country. Each country is proud of its genius. "Education which equates people with people", stated Auezov in his speech, a Kazakhstani writer. Assessment is important in the classroom at school every day. Assessment for learning is a process of developing and interpreting information that students and their teachers use to determine where they are in the learning process, in what direction they need to develop and how to reach the desired level.
\end{abstract}

Keywords: analysis, generalization, evaluation, methodological level.

Cite this article as: Aitzhanov A. (2020), Role of Education Assessment for Education Management. Challenges of Science. Issue III, 2020. Pp.: 27-30. https://doi.org/10.31643/2020.003

\section{Introduction}

According to the Russian pedagogue K. D. Ushinsky's speech, if every teacher is modern and uses the latest technologies in their classes more than the old one, the lesson will certainly be attractive, meaningful, convenient and effective. According to Article 8 of the Law of the Republic of Kazakhstan "On Education", "One of the main tasks of the education system is to introduce new technologies of education, informatization of education, and access to international global communication networks". As Our President Nazarbayev in his messagesaid, "To enter the civilized developed world in the future, we need modern education. Education that will bring Kazakhstan to the top 50 developed countries and equalize its windows. " Therefore, the current stage of development raises the issue of technologicalization of the educational process before the education system. The different teaching technologies are analyzed, the practices of innovative teachers are investigated, and they are entering the school life. In fact, everything in life is transient, not merely obsolete, but replenished and renewed. The methods of education are also changing and updating. There are many changes and reforms in education today.

\section{Research question and analysis of the Role of Education Assessment}

The eternal question of what to read is increasingly complicated: "What to teach, how to teach?" In order for a learner to become an individual, he or she must be able to learn the basics of learning voluntarily and to be able to apply the knowledge, purpose, objectives, forms, methods and activities of their activities in life. Our country also enhances the educational process for students by introducing the latest technology and teaching methods in the world. 
A teacher who plays a key role in promoting school performance and student achievement. The creative activity of a teacher is reflected, first of all, in his lessons and activities. Of course, in order to move forward, we need to evaluate, summarize, and evaluate the information and the work we have done.

Accurate assessment of student achievement is one of the key issues in the educational system. Student Assessment is the result of learning. Assessment of students' readiness and ability to attend is assessed. In traditional lessons, the knowledge of the students was evaluated only by the teacher. There were times when some of the students did not come up with the mark, and they said, "Why did you get it?" In some cases, I have had a hard time assessing the student's response. You want to rate well when the child is enthusiastic, but he / she may not be able to read the textbook properly and his or her knowledge seems to be weaker than the answers of other students, and you will not even know how much he or she will evaluate. When grading and assessing learning using the Assessment Module, students mark the mark for themselves and the pupil knows why they have scored in the grade criteria. Assessment for learning is the process of finding and interpreting information that students and their teachers use to determine where they are in the learning process, in what direction they need to develop and how to reach the desired level. All types of assessments include:

$>$ control

$>$ interpretation of the data received

$>$ summarizing possible decisions that will be taken to identify future actions.

Effective assessment of learning is linked to all new approaches to the educational process. Assessment is needed to identify and support progress in teaching. Students need to understand the criteria for achieving that goal. Because, when you do any business, you put criteria into it, and then you selfevaluate them, "Did I work in line with those requirements? To what extent have I done so? "and then take steps to succeed and move forward. Assessment is a term used to describe further activities that are aimed at systematically summarizing learning outcomes. / "Teacher's Guide" 3rd Edition, page 56 / That is, we know that assessment is an integral part of teaching and learning. So we need to understand that assessing learning is an improvement in education.

In my practice, I have mostly focused on systematically using learners' self, mutual, and peer assessment methods. This is because the learner is self-regulating and defining his or her level of education, comparing his / her knowledge with others. They will learn to understand and make a fair assessment of their mistakes. I have tried different assessment methods for children. My goal here is which one is best for assessment in teaching. At first, there was a problem with the grades, with the students giving themselves high marks and encouraging each other. During the lesson the students learned the importance of assessment. When evaluating words, ideas, ability to express their thoughts, behaviors, rules and more. When assessing each other, the learner will have different questions when assessing himself, based on the correctness of the answers in the notebook, without mistyping, that is, on the criteria. "Can I express my thoughts?", "Can I give clear evidence of my answer?", "How did I learn a new topic?", "How active were I?", "Could I listen to the opinions of others?", "Why did I do my homework?" Have I been serious about performing? ". As a result, the child becomes responsible, understands the need to improve his education, learn to analyze, compare his knowledge with others, and learn to make decisions during his education. Understand assessment to improve their education. This will allow them to further understand what they need to do to improve their results and their level of education. For example, some students write, "I couldn't answer the questions correctly in today's lesson", and when choosing the methods for the next lesson, make it easier for the student to answer them so that only accessible education is available. The teacher helps the student to become active and active in the classroom. When you complete your homework, the student's profound thoughts, unexpected views, and insights are amazed.

In assessment, they learn not only knowledge but also good interpersonal skills. For example, on a reflection page, Meyramgul wrote: "In this lesson, I had difficulty telling 2 stars in Sain's work because there were a lot of mistakes in his work, but when I came to assess him, I understood that there was more to good for a person than for the bad."

Assessment has shown that improving learning is one of the five key factors that look straightforward:

1. Providing effective feedback to students.

2. Active participation of students in independent learning.

3. Change learning based on assessment results.

4. Recognizing that assessment can have a significant impact on students' self-esteem and interest, which in turn has a fundamental effect on learning. 
5. Students need to be able to self-assess and understand how to improve their learning. / "Teacher's Guide" 2012 Edition III, Page 60 /

The evaluation process should be continuous, with deep focus, in class exercises, in order to ensure a reliable and fair assessment of the child's capabilities and achievements. I would like to point out that supporters of formative assessment do not reflect the exact knowledge of the learner: in trusting the learner and reflecting on them, they contribute to the formation of an individual who is confident in his / her knowledge, clear in purpose, able to distinguish between successes and failures. Price is the driving force in the learning process. From a critical standpoint, students are helping their students grow in knowledge and, as a result, see the results of our work and their professional growth. From that we must keep in mind that we are the main driving force in education. In order for our students and their students to reflect on the knowledge that we have given to them, we need to think about professional growth. The words of the great poet Abay, who said, "In essence, mankind surpasses mankind in its qualities of intelligence, knowledge, honor and character", have not always lost their relevance. Advanced thinking, knowledge contribute to the development and change of the world, society and society. That's why the qualitative growth of the teacher and the pupil, only when they are in harmony, can the quality change at the educational and methodological level.

\section{Assessment on "B. Bloom's taxonomy"}

In modern school practice, the American taxonomy of B. Bloom is used. It is a classification of criteria that characterize the level of knowledge and skills. This taxonomy is aimed at assessing the students' cognitive and emotional fields. Learning objectives in the cognitive field are considered at the person's level of knowledge and intelligence. The tasks related to the formation of intellectual skills and abilities are divided into: understanding $\rightarrow$ application $\rightarrow$ analysis $\rightarrow$ generalization $\rightarrow$ evaluation.

Mutual assessment helps students to provide feedback, meaning they can learn and support one another, discuss, talk, explain, and test each other. Qualitative mutual assessment contributes to the improvement of the quality of performance evaluation, which in turn enhances the responsibility of students for their advancement." The mark is set not on the student's weaknesses but on their further development. Marking is based on evaluation, and the child does not assess the next child, only evaluates.

Self-assessment can lead to self-regulation. Points can be calculated using the scoring scale.

Students ask questions

For example-

What do you want to know when reading a new topic?

$>$ Ask a teacher or other students for assessment of knowledge.

$>$ Identify areas of knowledge / misunderstandings that you would like to improve in the future.

Encourage students with limited abilities to ask a question using the "What" query, and encourage more accomplished students to ask a question like, "What ... what?"

"Basbarmak"

Check the level of comprehension of the students by explaining them to them.

For example:

$>$ Students have red, green and yellow cards which they can put on their sides or lift them up (red $=$ I do not understand, green $=$ everything is clear).

$>$ Students evaluate themselves using the colors of the traffic lights. The assessment given to the teacher may be recorded in the student diaries.

$>$ Classmates presentations using traffic lights, etc. appreciate.

At first, all children may be green. Then, those who can't find their mistake and then prove it wrong will go yellow or red. There are also difficulties with estimation. At the outset, children are highly rated; in that case, it is important for the students to tell the learner that the grade is true, and that the true grade shows how well they understand it.

Let's take a look at the advantages of the traditional formative assessment system:

Clearly describes the level of student achievement;

Increases motivation for education;

$>$ Students have red, green and yellow cards which they can put on their sides or lift them up ( $\mathrm{red}=\mathrm{I}$ do not understand, green $=$ everything is clear).

$>$ Students evaluate themselves using the colors of the traffic lights. The assessment given to the teacher may be recorded in the student diaries.

$>$ Classmates presentations using traffic lights, etc. appreciate. 
At first, all children may be green. Then, those who cannot find their mistake and then prove it wrong will go yellow or red.

\section{Conclusion and discussion}

There are also difficulties with estimation. At the outset, children are highly rated; in that case, it is important for the students to tell the learner that the grade is true, and that the true grade shows how well they understand it. Let's take a look at the advantages of the traditional formative assessment system:

Clearly describes the level of student achievement;

Increases motivation for education;

The current assessment must be in a variety of forms, understandable, psychologically comfortable, complex, or formative. The purpose of summative assessment or Assessment of Learning is to summarize what the student has learned at the moment. It can be done by a teacher in tests, exams etc. and evaluate it yourself.

The formative assessment is carried out at each lesson and every day. Assessment for learning is a process of developing and interpreting information that students and their teachers use to determine where they are in the learning process, in what direction they need to develop and how to reach the desired level. However, it is emphasized that teachers are not the only appraiser. Students can be involved in selfassessment and their peers, and students need to be active in the evaluation process. Let us be a teacher who is receptive to the news of his work, who wants to shine in the light of his disciples, and seeks to bring happiness and happiness to others.

Acknowledgments: This study was supported by the Ministery of Education and Science of the Republic of Kazakhstan at Abai Kazakh National Pedagogical University, while the author was studying his master's degree in the Department of Pedagogy and Psychology for the period 2018 and 2020.

Cite this article as: Aitzhanov A. (2020), Role of Education Assessment for Education Management. Challenges of Science. Issue III, 2020. Pp.: 27-30. https://doi.org/10.31643/2020.003

\section{Refrences}

Arpentieva, M. R., Kassymova, G., Kenzhaliyev, O., Retnawati, H., Kosherbayeva, A. (2019). Intersubjective Management in Educational Economy. Challenges of Science. https://doi.org/10.31643/2019.004

"Instruction for Teacher" 2012 edition III.

Atayeva, M., Putro, N. H. P. S., Kassymova, G., Kosbay, S. (2019). Impact of reading on students' writing ability. Challenges of Science. https://doi.org/10.31643/2019.001

Kassymova, G. (2018). Competence and its implications. Challenges of Science. https://doi.org/10.31643/2018.063

The purpose of the modern education system. Available at: https://en.wikipedia.org/wiki/EducationArpentieva, M. R.,

Triyono, B.M., Mohib, N., Kassymova, G.K., Pratama, G.N.I.P., Adinda D., Arpentieva, M.R. (2020). The Profile Improvement of Vocational School Teachers' Competencies. Vysshee obrazovanie v Rossii = Higher Education in Russia. Vol. 29, no. 2, pp. 151-158. https://doi.org/10.31992/0869-3617-2020-29-2-151-158 